Jurnal Geocelebes Vol. 3 No. 1, April 2019, 1 - 12

\title{
ANALISIS BAWAH PERMUKAAN PADA DAERAH PERENCANAAN PELABUHAN DENGAN MENGGUNAKAN METODE GEOLISTRIK DI KECAMATAN SANGA-SANGA KALIMANTAN TIMUR
}

\author{
Bambang Harimei $^{1 *}$, Samsu Arif ${ }^{2,3}$, Lantu $^{1}$ \\ ${ }^{1}$ Laboratorium Geofisika Padat, Universitas Hasanuddin, Makassar \\ ${ }^{2}$ Laboratorium Geoinformatika, Universitas Hasanuddin, Makassar \\ ${ }^{3}$ Pusat Studi Wilayah, Tata Ruang dan Informasi Spasial, Universitas Hasanuddin, Makassar \\ *Penulis koresponden. Alamat email: bambang_harimei2004@yahoo.com
}

\begin{abstract}
Abstrak
Penelitian bawah permukaan menggunakan metode geolistrik pada daerah perencanaan pelabuhan di Kecamatan Sanga-sanga Kalimantan Timur. Penelitian ini bertujuan mengetahui jenis dan profil tanah pada lokasi survei dengan cara membuat sebuah model lapisan bawah permukaan bumi dengan parameter arus dan tegangan listrik. Konfigurasi elektrode menggunakan konfigurasi elektrode Wenner-Alfa. Dari hasil dan pembahasan dapat ditarik kesimpulan antara lain; Semua jalur bentangan elektrode mempunyai variasi harga hambatan jenis batuan berkisar antara 5,56 - 7021 ohm $\mathrm{m}$ dan variasi harga hambatan jenis pada daerah penelitian mengindikasikan adanya pelapisan dari fresh groundwater, alluvium, clay, dolomite, limestone dan slate.
\end{abstract}

Kata Kunci: daerah bawah pelabuhan; komposisi batuan; variasi haga hambatan jenis batuan.

\begin{abstract}
The subsurface research uses the geoelectric method in the port planning area in Sanga-sanga District, East Kalimantan. This study aims to determine the type and profile of the soil at the survey location by making a model of the subsurface layer of the earth with current and potential parameters. The electrode configuration uses the Wenner-Alpha electrode configuration. The results and discussion conclude that the resistivity from all lines varies from 5.56 up to $7021 \mathrm{ohm} \mathrm{m}$. These values indicate the existence of fresh groundwater, alluvium, clay, dolomite, limestone, and slate.
\end{abstract}

Keywords: subsurface of the port area; rock composition; variation of rock resistivity. 


\section{Pendahuluan}

Pelabuhan yang cukup baik adalah pelabuhan yang kontruksi dapat menghindari terjadinya perubahan bentuk akibat tekanan dari kapal dan pergerakan lempeng tektonik. Dalam upaya mengurangi kegagalan konstruksi diperlukan pengetahuan tentang sifat mekanis dan elektrik batuan di bawah permukaan. Penelitian ini bertujuan untuk mengetahui sifat elektrik batuan penyusun profil tanah permukaan. Metode yang digunakan metode geolistrik dengan konfigurasi electrode Wenner Alfa.

Hukum Ohm sebagai prinsip dasar dari metoda geolistrik. Definisi dari Hukum Ohm adalah beda potensial yang timbul di ujungujung suatu medium berbanding lurus dengan arus listrik yang mengalir pada medium tersebut. Selain itu, tahanan listrik berbanding lurus dengan panjang medium dan berbanding terbalik dengan luas penampangnya. Adapun cara menentukan arus listrik yang terhambat di setiap lokasi dengan memberikan arus atau menginjeksikan arus listrik. Untuk menentukan berapa besar arus listrik terhambat pada batuan maka dipasangkan elektoda yang terbuat dari logam. Harga tahanan jenis akan diperoleh dari injeksi arus pada dua buah elektroda, kemudian harga tahanan jenis (Loke, 2004).

\section{Metode Penelitian}

Lokasi penelitian di Kelurahan Pendingin, Kecamatan Sanga-sanga, Kabupaten Kutai Kartanegara dan Provinsi Kalimantan Timur.

Gambar 1 memperlihatkan batas-batas lokasi penelitian dan koordinatnya dalam Tabel 1. Koordinat yang digunakan adalah Universal Transvers Mercator (UTM).

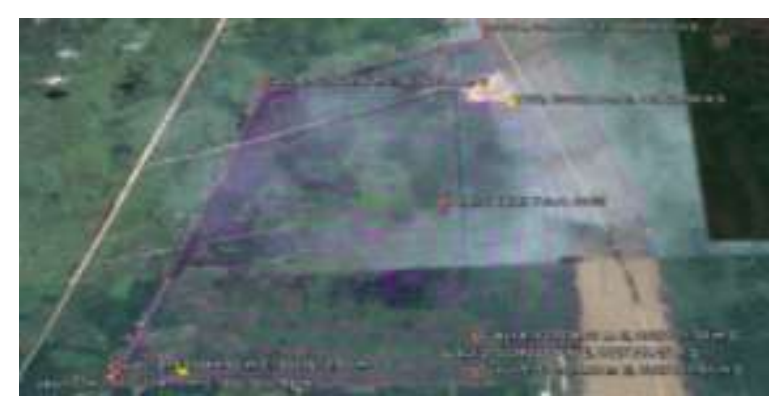

Gambar 1. Peta lokasi penelitian

Tabel 1. Batas - batas lokasi penelitian

\begin{tabular}{cccc}
\hline No. & Batas & Timur $($ East $)$ & Utara $($ North $)$ \\
\hline 1 & 1 & 531620.7 & 9929785.04 \\
\hline 2 & 2 & 532992.8 & 9930295.97 \\
\hline 3 & 3 & 533437.09 & 9927826.25 \\
\hline 4 & 4 & 532924.01 & 9927821.39 \\
\hline 5 & 5 & 532925.21 & 9927601.91 \\
\hline 6 & 6 & 531045.00 & 9927612.00 \\
\hline
\end{tabular}

\section{Pengumpulan Data}

Data diambil secara langsung di lapangan. Adapun data yang diambil berupa data topografi detail dan data pengukuran geolistrik tahanan jenis. Tahapan pengumpulan data yaitu:

\section{Pemetaan topografi skala detail}

Pemetaan topografi skala detail pada lokasi penelitian di Kelurahan Pendingin, Kecamatan Sanga-sanga, Kabupaten Kutai kartanegara, Kalimantan Timur. Metode pemetaan topografi dilakukan dengan metode random traverse dengan menggunakan GPS Geodetic. Pengumpulan data dilakukan 5 bentangan kabel (jalur) pada di koordinat 531374,11 $\mathrm{m}$ E, 9929628,00 m $\mathrm{N}$ dan diberi nama jalur 1,2,3,4 dan 5.5 jalur berikutnya berada pada koordinat 531045,00 m E 9927632,89 m N diberi nama jalur 6,7, 8, 9 , dan 10 .

2. Pengukuran geolistrik tahanan jenis daerah penelitian.

Jalur pengukuran geolistrik tahanan jenis sejajar dan tegak lurus terhadap garis pantai, 
dengan mengunakan metode pengukuran Wenner - Alfa (2D). Data yang diperoleh berupa harga besar arus dan beda potensial (Syamsuddin, 2007).

\section{Konfigurasi Wenner-Alfa}

Konfigurasi Wenner - Alfa bertanda konfigurasi elektroda potensial berada di antara elektroda arus yang tersusun dari $\mathrm{C} 1$ - P1 - P2 - C2. Jarak elektroda yang satu dengan lainnya sama dengan a, seperti terlihat pada Gambar 2. Faktor geometri konfigurasi ini adalah $k=2 \pi a$ (Taib, 2004).

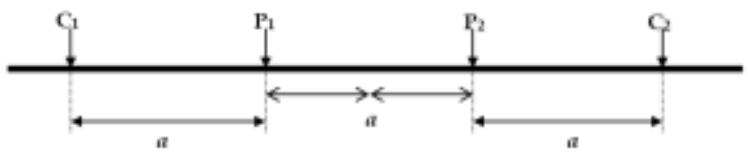

Gambar 2. Konfigurasi eletroda Wenner-Alfa

\section{Pengolahan Data}

Data berupa variasi harga tahanan jenis batuan pada daerah penelitian. Data tersebut dimasukkan ke komputer dengan perangkat lunak RES2Dinv. Data yang dihasilkan berupa variasi lapisan batuan berdasarkan variasi tahanan jenis batuan bawah permukaan. Variasi harga tahanan jenis batuan dapat dilihat dalam Gambar 3.

\section{Hasil dan Pembahasan}

Hasil yang diperoleh pada jalur 1 dapat dilihat dalam Gambar 4.

Gambar 4 didominasi berwarna ultraviolet pada kedalaman 15 -20 meter dengan nilai hambatan jenis $106-200$ ohm m. Fresh groundwater dan jenis batuan sandstone, shale, limestone dan dolomite. Adapun keselurahan data variasi harga hambatan jenis jalur 1 dapat dilihat dalam Tabel 2 .

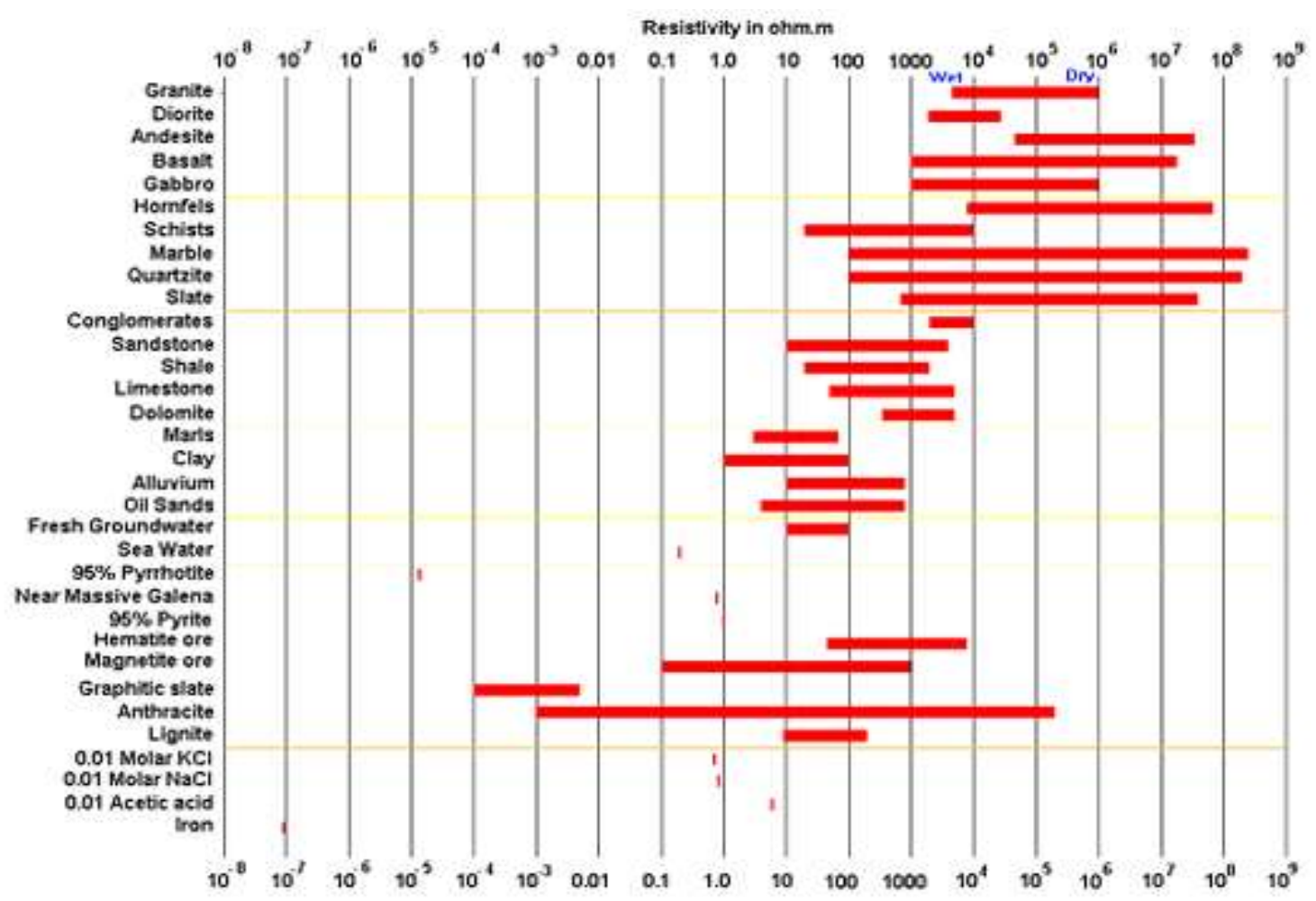

Gambar 3. Variasi harga tahanan jenis batuan (Loke, 2004) 


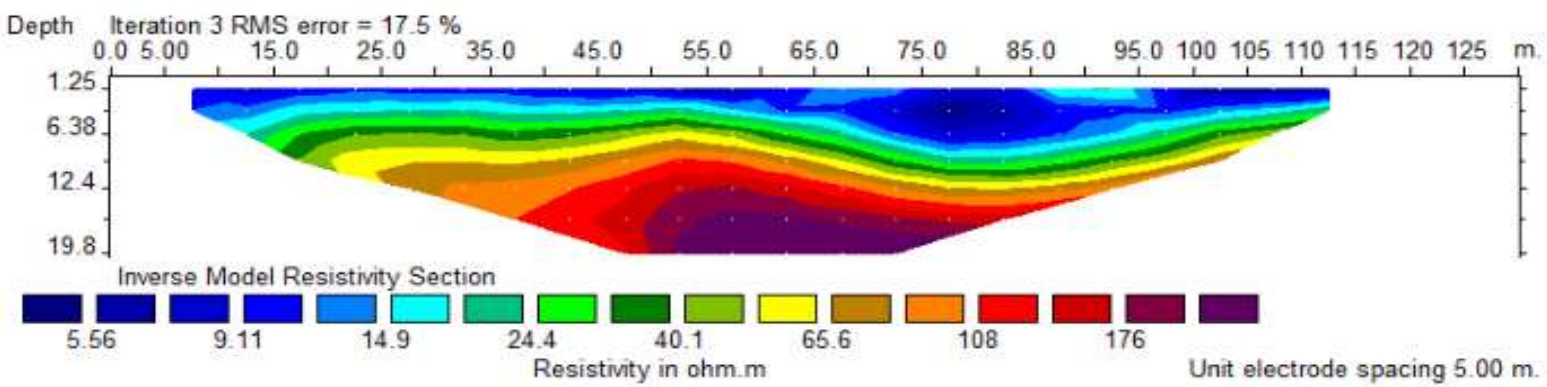

Gambar 4. Jalur elektroda 1 arah B-T pada koordinat 533127,00 E 9929628,00 N

Tabel 2. Jenis batuan pada jalur 1 berdasarkan harga hambatan jenis

\begin{tabular}{cccl}
\hline No. & Kedalaman (meter) & Resistivitas $(\mathbf{O h m} \mathbf{m})$ & \multicolumn{1}{c}{ Nama Batuan } \\
\hline 1 & $1,25-2$ & $5,56-15$ & Fresh groundwater \\
\hline 2 & $2,15-6,5$ & $15,2-15,5$ & Shale \\
\hline 3 & $6,6-12,4$ & $16,1-70,5$ & Limestone \\
\hline 4 & $12,5-20$ & $>71$ & Dolomite \\
\hline
\end{tabular}

Pada jalur 2 arah bentangan kabel Barat Timur, adapun lokasi jalur 2 berkoordinat dengan jalur 1 tetapi berjarak 120 meter dalam arah Barat Ke Timur. Gambar 5 mempelihatkan hasil yang diperoleh pengukuran jalur 2 .
Pada jalur 2 paling atas adalah Fresh groundwater (air) ditandai dengan warna biru dan paling dalam adalah shale ditandai warna ultraviolet (ultraungu). Fresh groundwater dan jenis batuan sandstone, shale, limestone dan dolomite.

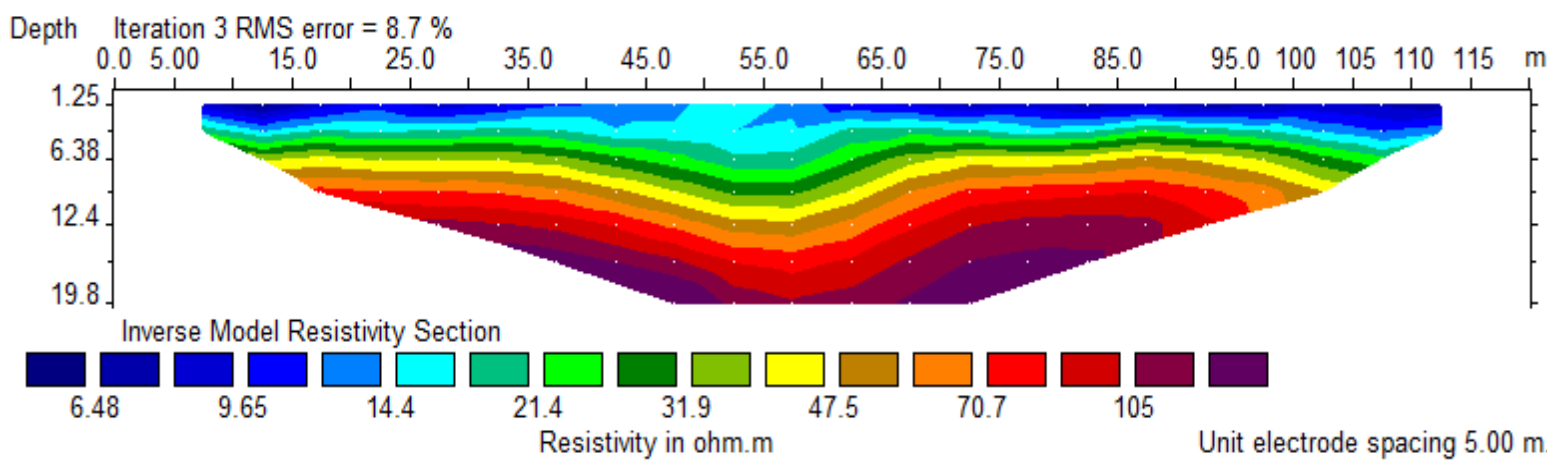

Gambar 5. Jalur elektrode 2 arah B-T pada koordinat 533127,00 m E 9929628,00 m N

Tabel 3. Jenis batuan pada jalur 2 berdasarkan harga hambatan jenis

\begin{tabular}{cccl}
\hline No. & Kedalaman (meter) & Resistivitas $(\mathbf{O h m} \mathbf{~ m})$ & \multicolumn{1}{c}{ Nama Batuan } \\
\hline 1 & $1,25-2$ & $5,56-15$ & Fresh groundwater \\
\hline 2 & $2,15-6,5$ & $15,2-15,5$ & Shale \\
\hline 3 & $6,6-12,4$ & $16,1-70,5$ & Limestone \\
\hline 4 & $12,5-20$ & $>71$ & Clay \\
\hline
\end{tabular}

Tabel 3 memperlihatkan susunan yang terdiri dari fresh groundwater, shale, limestone. Pada jalur ini belum terbentuk batuan dolomite.
Berikutnya dilakukan penentuan harga tahanan jenis batuan di jalur 3 dengan koordinat 533127,00 m E 9929628,00 m N. 
Adapun hasil dari pengukuran hambatan jenis batuan dapat dilihat dalam Gambar 6.

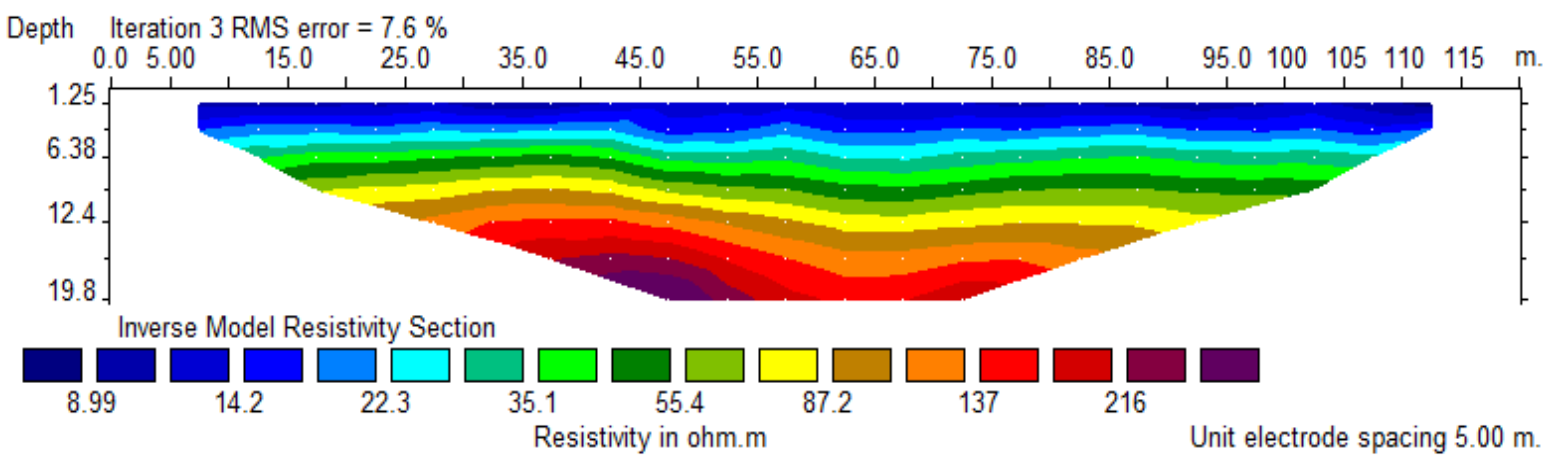

Gambar 6. Jalur elektrode 3 arah U-S pada Koordinat 533127,00 m E 9929628,00 m N

Tabel 4. Jenis batuan dalam jalur 3 berdasarkan hambatan jenis

\begin{tabular}{cccl}
\hline No. & Kedalaman (meter) & Resistivitas $(\mathbf{O h m} \mathbf{m})$ & \multicolumn{1}{c}{ Nama Batuan } \\
\hline 1 & $1,25-2$ & $<8,5$ & Fresh groundwater \\
\hline 2 & $2,15-6,5$ & $10,2-25,5$ & Limestone \\
\hline 3 & $6,6-12,4$ & $26,5-138$ & Dolomite \\
\hline 4 & $12,5-20$ & $>216$ & Clay \\
\hline
\end{tabular}

Jalur 3 batuan yang mempunyai variasi harga tahanan jenis antara $<8,5 \mathrm{ohm} \mathrm{m}$ sampai > 216 ohm m, ditandai warna biru. Adapun hasil lengkapnya dilihat dalam Tabel 4.
Tabel 4 memperlihatkan susunan batuan yang ada dalam jalur 3, didahului Fresh groundwater, limestone, dolomite dan clay. Berikut ini diperlihatkan hasil survei pada jalur 4, posisi koordinat jalur 4 adalah

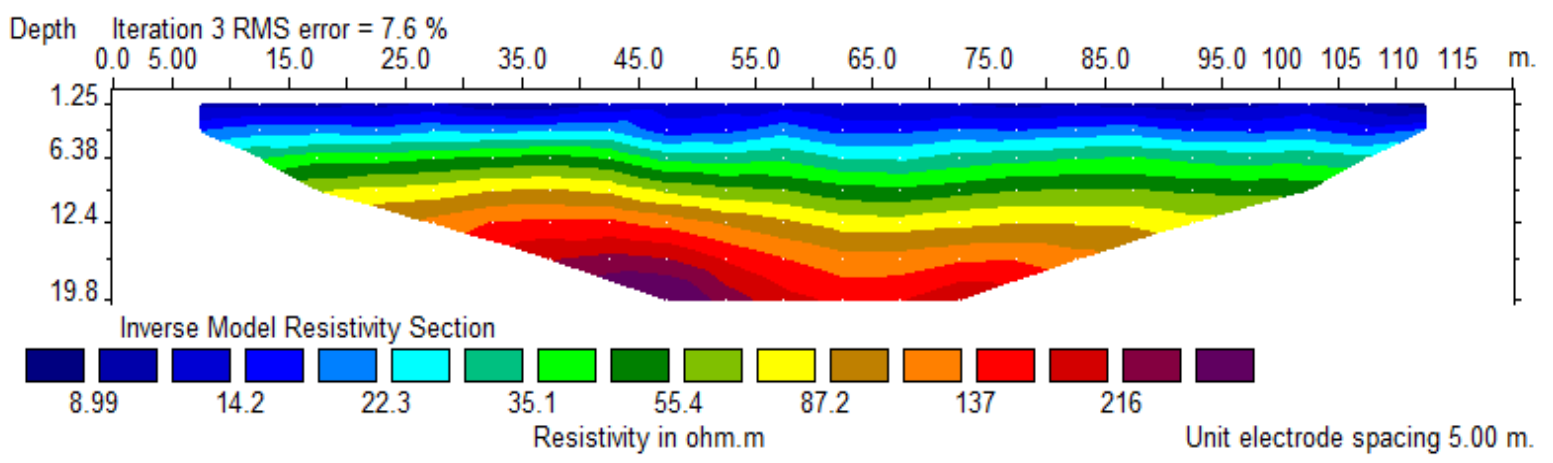

Gambar 7. Jalur elektrode 4 arah U-S pada koordinat 533127,00 m E 9929628,00 m N

Tabel 5. Jenis batuan dalam jalur 3 berdasarkan hambatan jenis

\begin{tabular}{cccl}
\hline No. & Kedalaman (meter) & Resistivitas $($ Ohm m) & \multicolumn{1}{c}{ Nama Batuan } \\
\hline 1 & $1,25-2$ & $<8,99$ & Fresh groundwater \\
\hline 2 & $2,15-6,5$ & $14,4-25,5$ & Alluvium \\
\hline 3 & $6,6-12,4$ & $35,5-138$ & Clay \\
\hline 4 & $12,5-20$ & $>216$ & Shale \\
\hline
\end{tabular}


$533127.00 \mathrm{~m}$ E $9929628.00 \mathrm{~m} \mathrm{~N}$, arah bentangan elektroda dari Utara ke Selatan berjarak 120 meter dari jalur 3. Adapun hasil survei dapat dilihat Gambar 7.

Gambar 7 mempelihatkan susunan batuan pada jalur 4 survey didominasi fresh clay berada di kedalaman 20 meter. Untuk lebih detailnya dapat di lihat dalam Tabel 5 .

Tabel 5 memperlihatkan susunan batuan yang ada dalam jalur 4, didahului oleh Fresh groundwater, air berada di bawah Alluvium, posisi ini mengakibatkan terbentuknya Clay.
Pada titik koordinat $533127.00 \quad \mathrm{~m} \quad \mathrm{E}$ $9929628.00 \mathrm{~m} \mathrm{~N}$ maka dilakukan survei dengan jalur diagonal dari ujung jalur 1 (Utara) ke ujung jalur (Selatan). Adapun hasil dapat dilihat pada gambar 8 .

Harga hambatan jenis pada jalur 5 paling kecil sebesar $<8,5 \mathrm{ohm} \mathrm{m}$ dan terbesar $>216$ $\mathrm{ohm} \mathrm{m}$. Untuk detailnya dapat dilihat dalam Tabel 6 .

Tabel 6 memperlihatkan susunan batuan yang ada dalam jalur 5, susunan sama seperti susunan batuan pada jalur 4 .

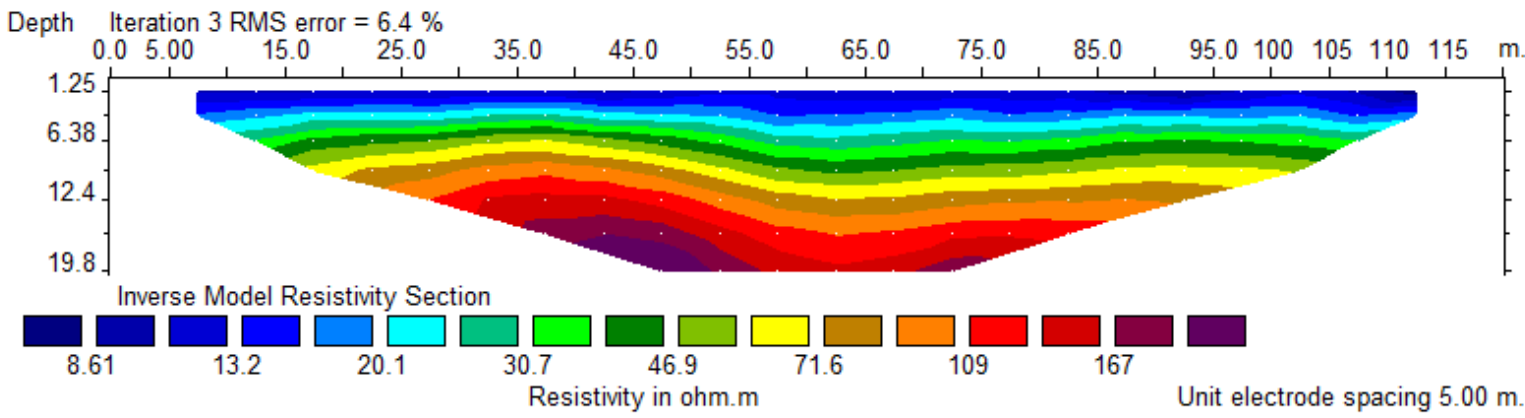

Gambar 8. Jalur elektrode 5 arah diagonal koordinat 533127,00 m E $9929628,00 \mathrm{~m} \mathrm{~N}$

Tabel 6. Jenis material yang ada dalam jalur 5 berdasarkan hambatan jenis

\begin{tabular}{cccl}
\hline No. & Kedalaman (meter) & Resistivitas $(\mathbf{O h m} \mathbf{~ m})$ & Nama Material \\
\hline 1 & $1,25-2$ & $<8,5$ & Fresh groundwater \\
\hline 2 & $2,15-6,5$ & $10,2-25,5$ & Alluvium \\
\hline 3 & $6,6-12,4$ & $26,5-138$ & Clay \\
\hline 4 & $12,5-20$ & $>216$ & Shale \\
\hline
\end{tabular}

Selanjutnya, pengukuran di 80 meter dari tepi sungai atau koordinat $533127.00 \mathrm{~m} \mathrm{E}$ $9929628.00 \mathrm{~m} \mathrm{~N}$. Adapun hasil survei dapat dilihat pada Gambar 9.

Gambar 9 memperlihatkan batuan mempunyai harga hambatan jenis paling kecil < 12,3 m pada $1,25-2 \mathrm{~m}$ dan terbesar > $334 \mathrm{ohm} \mathrm{m}$ dengan kedalaman $12,5-20 \mathrm{~m}$. Hasil secara terperinci lihat Tabel 7.
Tabel 7 memperlihatkan susunan batuan yang ada dalam jalur 6, fresh groundwater yang membawa mineral - mineral mendapat suhu yang tinggi dan tekanan sehingga pengendapannya menjadi Alluvium, Shale dan Clay. 


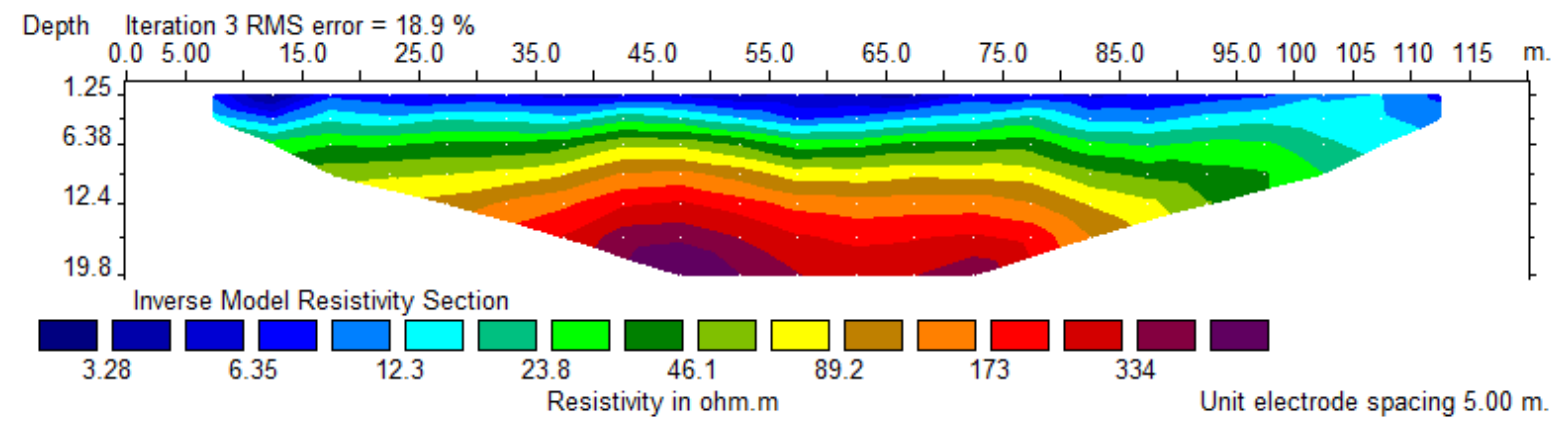

Gambar 9. Jalur elektrode 6 arah T-B koordinat 533127,00 m E 9929628,00 m N

Tabel 7. Jenis batuan yang ada dalam jalur 6 berdasarkan hambatan jenis

\begin{tabular}{cccl}
\hline No. & Kedalaman (meter) & Resistivitas (Ohm m) & \multicolumn{1}{c}{ Nama Material } \\
\hline 1 & $1,25-2$ & $<12,3$ & Fresh groundwater \\
\hline 2 & $2,15-6,5$ & $14,2-46,2$ & Alluvium \\
\hline 3 & $6,6-12,4$ & $46,5-333$ & Clay dan Shale \\
\hline 4 & $12,5-20$ & $>334$ & Shale \\
\hline
\end{tabular}

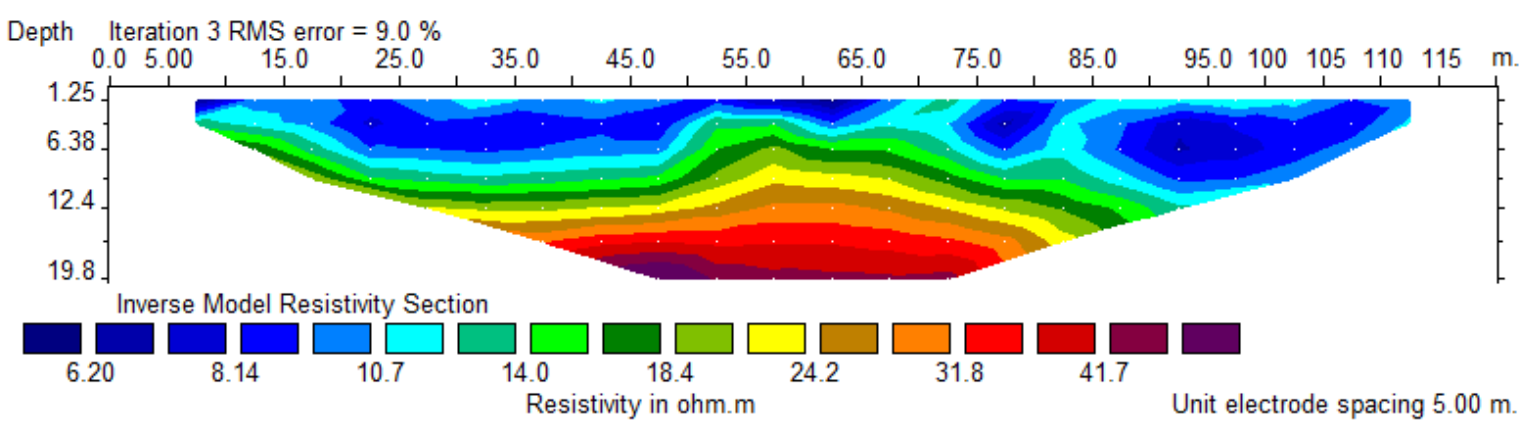

Gambar 10. Jalur elektrode 7 arah T-B koordinat 533127,00 m E 9929628,00 m N

Tabel 8. Jenis batuan yang ada dalam jalur 7 berdasarkan hambatan jenis

\begin{tabular}{cccl}
\hline No. & Kedalaman (meter) & Resistivitas $(\mathbf{O h m} \mathbf{~ m )}$ & \multicolumn{1}{c}{ Nama Material } \\
\hline 1 & $1,25-2$ & $<7,3$ & Fresh groundwater \\
\hline 2 & $2,15-6,5$ & $7,5-18,4$ & Alluvium \\
\hline 3 & $6,6-12,4$ & $18,5-41,7$ & Alluvium dan Clay \\
\hline 4 & $12,5-20$ & $>42$ & Clay \\
\hline
\end{tabular}

Jalur 7 berjarak berjarak 120 meter dengan arah Barat ke Timur pada koordinat yang sama dengan jalur 6. Adapun hasil dapat dilihat pada Gambar 10.

Gambar 10 memperlihatkan batuan yang ada di bawah permukaan jalur 7 pada kedalaman $1,25-12,4 \mathrm{~m}$ dan mempunyai harga hambatan jenis $6,20-10,7 \mathrm{ohm}$ m dengan warna biru. Hal ini sebagai indikasi dari adanya fresh groundwater. Pada kedalaman 19,8 meter atau lebih terdapat clay. Adapun detail dari sebaran material pada jalur 7 dapat dilihat Tabel 8 .

Tabel 8 memperlihatkan susunan batuan yang ada dalam jalur 7 , komposisi batuan sama seperti batuan yang ada dalam jalur 6 . 
Namun kedalamannya berbeda. Jalur 8 berkoordinat $533127.00 \mathrm{~m} \mathrm{E} 9929628.00 \mathrm{~m}$ $\mathrm{N}$ dan arah bentangannya Utara ke Selatan. Adapun hasilnya dapat dilihat pada Gambar 11 .
Gambar 11 memperlihatkan harga hambatan jenis batuan pada jalur 8. Paling atas mempunyai hambatan jenis yang terkecil, lebih kecil 6,20 ohm m pada kedalaman $1,25-2 \mathrm{~m}$ dan yang terbesar $>41,3 \mathrm{Ohm} \mathrm{m}$ pada kedalaman 12,5-20 m. Untuk lebih jelasnya dapat dilihat Tabel 9 .

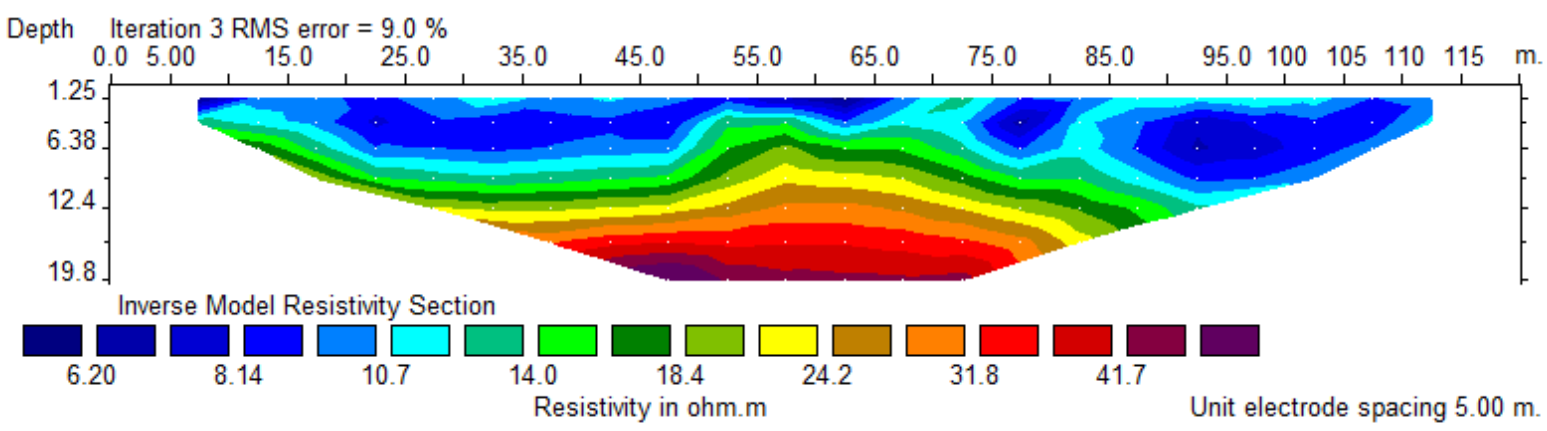

Gambar 11. Jalur electrode 8 arah U-S koordinat 533127,00 m E 9929628,00 m N

Tabel 9. Jenis material yang ada dalam jalur 8 berdasarkan hambatan jenis

\begin{tabular}{cccl}
\hline No. & Kedalaman (meter) & Resistivitas (Ohm m) & \multicolumn{1}{c}{ Nama Material } \\
\hline 1 & $1,25-2$ & $<6,2$ & Fresh groundwater \\
\hline 2 & $2,15-6,5$ & $8,24-16,0$ & Alluvium dan clay \\
\hline 3 & $6,6-12,4$ & $15,8-31,5$ & Alluvium \\
\hline 4 & $12,5-20$ & $>41,2$ & Clay \\
\hline
\end{tabular}

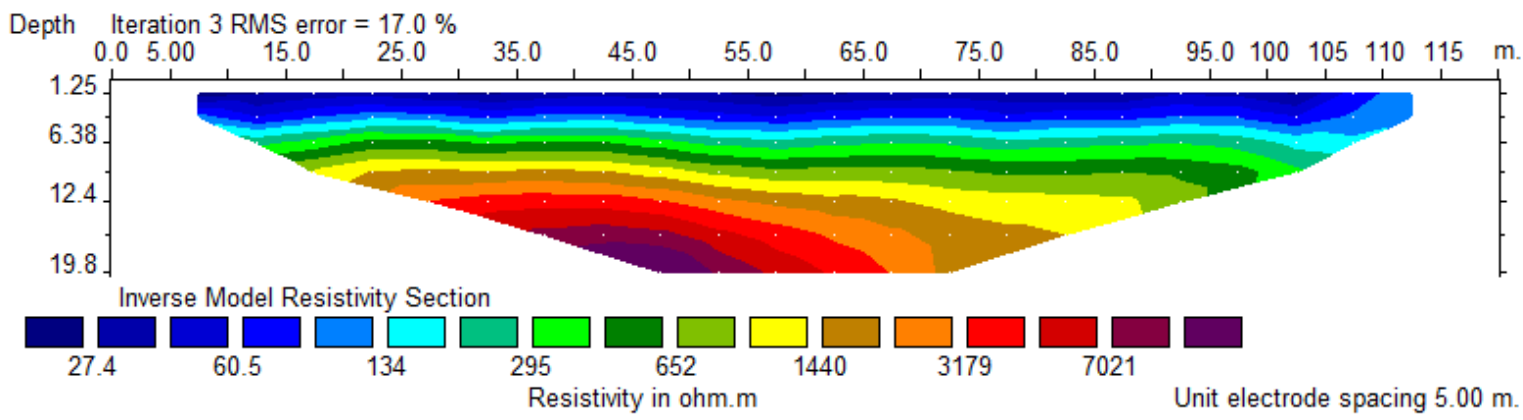

Gambar 12. Jalur electrode 9 arah U-S koordinat 533127,00 m E 9929628,00 m N

Tabel 10. Jenis material yang ada dalam jalur 9 berdasarkan hambatan jenis

\begin{tabular}{cccl}
\hline No. & Kedalaman (meter) & Resistivitas $(\mathbf{O h m} \mathbf{~ m})$ & \multicolumn{1}{c}{ Nama Material } \\
\hline 1 & $1,25-2$ & $<27,4$ & Fresh groundwater \\
\hline 2 & $2,15-6,5$ & $28,5-134$ & Clay \\
\hline 3 & $6,6-12,4$ & $296-3179$ & Limestone \\
\hline 4 & $12,5-20$ & $>7021$ & Conglomerates \\
\hline
\end{tabular}

Tabel 9 memperlihatkan harga hambatan jenis batuan dan kedalaman sama seperti pada jalur 7. Selanjutnya jalur 9. Adapun sebaran dapat dilihat pada Gambar 12. 
Gambar 12 memperlihatkan harga hambatan jenis batuan yang paling kecil $<27,4 \mathrm{ohm} \mathrm{m}$ dengan kedalaman 1,25 - 223,5 $\mathrm{m}$ dan yang terbesar > $7021 \mathrm{ohm}$ m kedalaman 12,5 - 20 $\mathrm{m}$. Untuk lebih jelas dapat dilihat dalam Tabel 10.
Tabel 10 memperlihatkan variasi harga hambatan jenis batuan pada jalur 9. Pada jalur ini terdapat batuan conglomerate. Pengukuran selanjutnya dilakukan pengukuran jalur diagonal. Adapun hasilnya dapat dilihat Gambar 13.

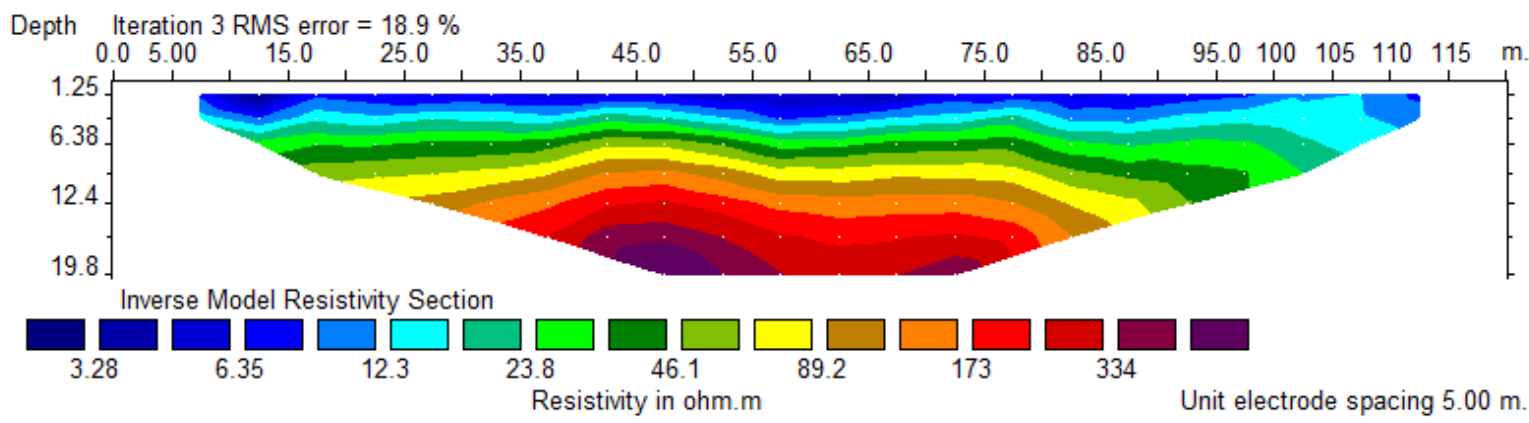

Gambar 13. Jalur electrode 10 arah diagonal koordinat 533127,00 m E 9929628,00 m N

Tabel 11. Jenis material yang ada dalam jalur 10 berdasarkan hambatan jenis

\begin{tabular}{cccl}
\hline No. & Kedalaman (meter) & Resistivitas (Ohm m) & Nama Material \\
\hline 1 & $1,25-2$ & $<2,4$ & Fresh groundwater \\
\hline 2 & $2,15-6,5$ & $28,5-134$ & Alluvium dan clay \\
\hline 3 & $6,6-12,4$ & $296-3179$ & Alluvium \\
\hline 4 & $12,5-20$ & $>7021$ & Slate \\
\hline
\end{tabular}

Jalur 10 dapat dilihat bahwa hambatan jenis warna biru berharga $3-20 \mathrm{ohm}$ m sampai $6,36 \mathrm{ohm} \mathrm{m}$, hal ini sebagai indikasi dari fresh groundwater dan paling dalam ditempati Clay dengan nilai hambatan jenis lebih dari $334 \mathrm{ohm} \mathrm{m}$. Untuk lebih detailnya dapat dilihat dalam Tabel 11.

Tabel 11 mempelihatkan komposisi batuan di bawah permukaan, di jalur terdapat konglomerat. Hal ini karena lokasi pengambilan data di dekat delta Sungai Mahakam sehingga sangat dimungkinkan terbentuknya batu slate.

Dalam rangka memperjelas jenis mineral di daerah penelitian, maka jalur 1, 2, 3, 4 dan 5 disatukan. Adapun hasil penyatuannya dapat dilhat dalam Gambar 14.
Gambar 14 memperlihatkan penyatuan jalur 1 sampai jalur 5. Perlapisan bawah permukaan yang berjarak 80 meter dari tepi sungai delta Mahakam secara berturut-turut adalah fresh groundwater, limestone, alluvium, clay, dolomite, dan sandstone.

Keberadaan dari fresh groundwater sebagai akibat dari intrusi air laut ke daratan. Air laut membawa mineral - mineral kemudian air laut diendapkan hingga menjadi alluvium. Adapun komposisi kimia dari alluvium yang diangkut oleh air laut adalah kalsium karbonat. Pada akhir pengendapan kalsium karbonat menjadi batugamping (limestone).

Batugamping mendapat perubahan suhu dan tekanan sehingga mineral - mineral kalsit meninggalkan batugamping dan tempatnya 


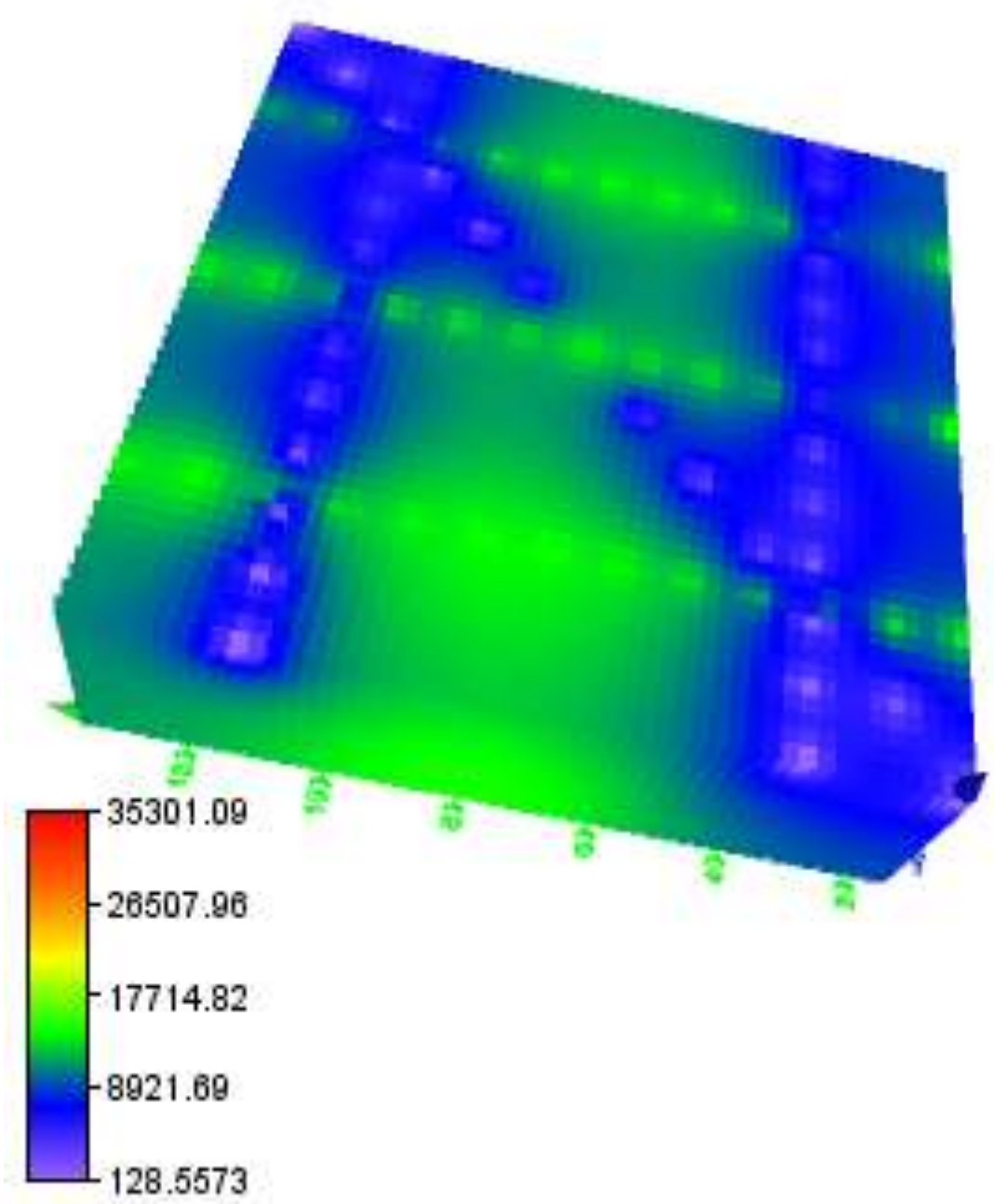

Gambar 14. Tampak atas dari gabungan dari lima jalur elektode pada koordinat $533127.00 \mathrm{~m} \mathrm{E} 9929628.00 \mathrm{~m}$ $\mathrm{N}$

digantikan oleh Dolomit. Dolomit jenis ini adalah Dolomit sekunder. Di samping itu, pengaruh suhu dan tekanan mengakibatkan proses penghabluran ulang (recrystallization) pada proses ini menghasilkan endapan lumpur (shale). (Surya dkk., 2018)

Pada sisi alterasi dan pelapukan dari limestone dan shale menghasilkan lempung (clay) dengen komposisi illit dan vermikulit, dan salah satu dapat teralterasi lebih lanjut menjadi montmorillonit dan klorit. (Utami, 2018).
Berdasarkan tingkat kekerasan clay dan shale dalam pada pengujian Direct Shear didapatkan nilai persentase sebesar 10 $25 \%$. Nilai tersebut mengindikasikan bahwa clay dan shale dapat digunakan sebagai bahan referensi dalam perencanaan geoteknik (Wirmanda dkk., 2017).

Limestone pada daerah penelitian diperoleh nilai kuat tekan 1,3 - 2,9 $\mathrm{MPa}$ dan dapat diartikan bahwa secara umum mempunyai kekuatan massa batuan yang sedang, sehingga tidak berpotensi terjadi amblesan bila diberi beban tiang pancang (Wijaya dan Isnawan, 2015). 
Berikutnya, penyatuan jalur $6,7,8,9$ dan 10. Berkoordinat $533127.00 \mathrm{~m}$ E $9929628.00 \mathrm{~m} \mathrm{~N}$. Adapun hasilnya dapat dilihat dalam Gambar 15.

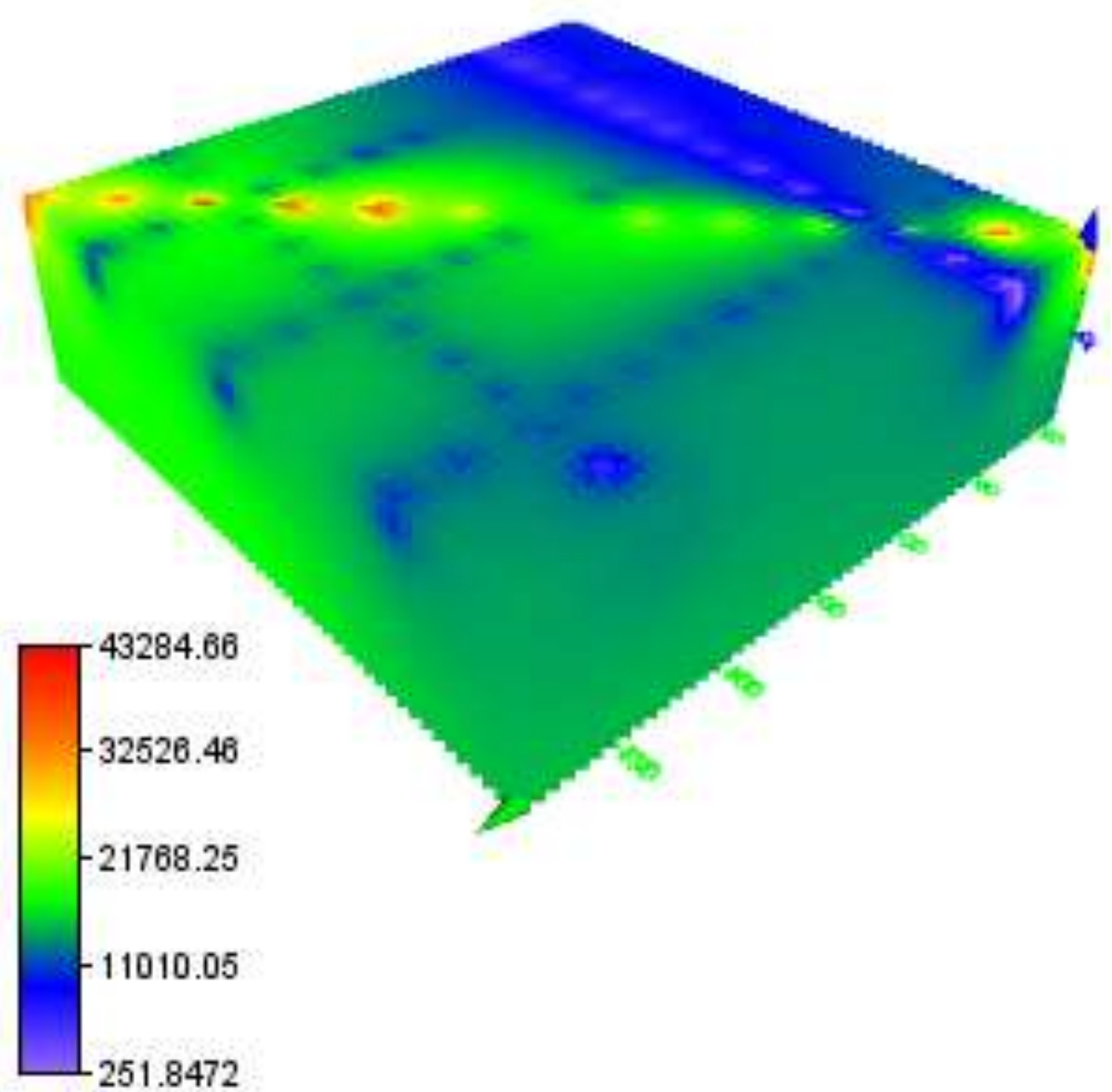

Gambar 15. Tampak atas dari gabungan dari lima jalur elektode pada koordinat 533127.00 m E $9929628.00 \mathrm{~m}$ $\mathrm{N}$

Posisi jalur pengukuran resistivity 80 meter dari tepi delta Sungai Mahakam. Adapun sebaran batuan dan mineral yang ada pada penggabungan jalur adalah fresh groundwater, limestone, clay, Alluvium dan slate (sabak).

Keberadaan batu sabak berasal dari perubahan serpih atau kerikil lumpur dengan metamorfisme regional tingkat rendah. Sedangkan genesa pembentukan batu sabak dari lingkungan tektonik yang menghasilkan kerikil sabak biasanya ialah bekas cekungan sedimen yang terlibat dalam lempeng konvergen. Serpih maupun kerikil lumpur di dalam cekungan akan tertekan oleh gaya horizontal sehingga mengalami sedikit kenaikan. 


\section{Kesimpulan}

Dari hasil dan pembahasan dapat ditarik beberapa kesimpulan antara lain:

1. Semua jalur elektroda mempunyai variasi harga hambatan jenis batuan berkisar antara 5,56-7021 ohm $\mathrm{m}$.

2. Variasi harga hambatan jenis pada daerah penelitian mengindikasikan adanya pelapisan fresh groundwater, alluvium, clay, dolomite, limestone dan slate.

\section{Saran}

Komposisi batuan pada bawah permukaan daerah penelitian dalam kategori baik sesuai apabila diperuntukan bagi kawasan pelabuhan.

\section{Ucapan Terima Kasih}

Ucapan terima kasih ditujukan kepada: PT. Celebes Pratama Kosultan dan Dinas Perhubungan Laut dan Sungai Kabupaten Kutai Kartanegera Provinsi Kalimantan Timur yang telah memberi kesempatan dalam melakukan penelitian.

\section{Daftar Pustaka}

Loke, M.H. 2004. 2-D and 3-D Electrical Imaging Surveys. Tutorial. Email: drmhloke@yahoo.com.

Surya, D.H., Abdurrokhim, Haryanto, I. 2018. Dolomitasi Batugamping Formasi Klapanunggal Cekungan Bogor, Jawa Barat. Bulletin of Scientific Contribution: Geology. 16(1), pp.33-38.

Syamsuddin. 2007. Penentuan Struktur Bawah Permukaan Bumi Dangkal Dengan Menggunakan Metoda Geolistrik Tahanan Jenis 2D Studi Kasus Potensi Tanah Longsor di Panawangan, Ciamis. Tesis. Institut Teknologi Bandung.
Taib, M.I.T. 2004. Eksplorasi Geolistrik, Diktat Kuliah Metoda Geolistrik, Departemen Teknik Geofisika, ITB, Bandung.

Utami, D.N. 2018. Kajian Jenis Mineralogi Lempung dan Implikasinya Dengan Gerakan Tanah. Jurnal Alami. 2(2), pp.89-97.

Wijaya, R.A.E., Isnawan, D. 2015. Analisis Kekuatan Massa Batugamping Dengan Menggunakan Kaidah HoekBrown Failure Criterion-Roclab di Daerah Gunung Sudo Kabupaten Gunung Kidul Yogyakarta. Jurnal Promine. 3(1), pp. 21-35.

Wirmanda, A.Y., Fathullah, I.D., Hardiyati, S., Wikan S, K. 2017. Perilaku Clay Shale Terhadap kuat Geser Rsidual Pada Lokasi Banyumeneng, Penawangan Dan Wonosegoro. Jurnal Karya Teknik Sipil. 6(3), pp. 81-92. 